\title{
Ex vivo infection of murine precision-cut lung tissue slices with Mycobacterium abscessus: a model to study antimycobacterial agents
}

\author{
Carmen Amelia Molina-Torres ${ }^{1}$, Oscar Noé Flores-Castillo² Irma Edith Carranza-Torres ${ }^{2,3}$, \\ Nancy Elena Guzmán-Delgado ${ }^{4}$, Ezequiel Viveros-Valdez ${ }^{2}$, Lucio Vera-Cabrera ${ }^{1}$, Jorge Ocampo-Candiani ${ }^{1}$, \\ Julia Verde-Star ${ }^{2}$, Jorge Castro-Garza ${ }^{3}$ and Pilar Carranza-Rosales ${ }^{3^{*}}$ (D)
}

\begin{abstract}
Background: Multidrug-resistant infections due to Mycobacterium abscessus often require complex and prolonged regimens for treatment. Here, we report the evaluation of a new ex vivo antimicrobial susceptibility testing model using organotypic cultures of murine precision-cut lung slices, an experimental model in which metabolic activity, and all the usual cell types of the organ are found while the tissue architecture and the interactions between the different cells are maintained.

Methods: Precision cut lung slices (PCLS) were prepared from the lungs of wild type BALB/c mice using the Krumdieck ${ }^{\circledR}$ tissue slicer. Lung tissue slices were ex vivo infected with the virulent M. abscessus strain L948. Then, we tested the antimicrobial activity of two drugs: imipenem $(4,16$ and $64 \mu \mathrm{g} / \mathrm{mL})$ and tigecycline $(0.25,1 \mathrm{and} 4 \mu \mathrm{g} / \mathrm{mL})$, at 12, 24 and $48 \mathrm{~h}$. Afterwards, CFUs were determined plating on blood agar to measure the surviving intracellular bacteria. The viability of PCLS was assessed by Alamar Blue assay and corroborated using histopathological analysis.

Results: PCLS were successfully infected with a virulent strain of M. abscessus as demonstrated by CFUs and detailed histopathological analysis. The time-course infection, including tissue damage, parallels in vivo findings reported in genetically modified murine models for $M$. abscessus infection. Tigecycline showed a bactericidal effect at $48 \mathrm{~h}$ that achieved a reduction of $>4 \log _{10} \mathrm{CFU} / \mathrm{mL}$ against the intracellular mycobacteria, while imipenem showed a bacteriostatic effect.
\end{abstract}

Conclusions: The use of this new organotypic ex vivo model provides the opportunity to test new drugs against $M$. abscessus, decreasing the use of costly and tedious animal models.

Keywords: Mycobacterium abscessus, Lung tissue slices, Ex vivo infection

\section{Background}

Mycobacterium abscessus is an important emerging pathogen responsible for a wide spectrum of diseases, including chronic pulmonary disease, and skin and

*Correspondence: carranza60@yahoo.com.mx

${ }^{3}$ Centro de Investigación Biomédica del Noreste, Instituto Mexicano del Seguro Social, Monterrey, NL, México

Full list of author information is available at the end of the article soft tissue infections. M. abscessus is a nontuberculous mycobacteria (NTM) found in soil and water, including municipal and household water supply systems. This species is one of the most resistant organisms to chemotherapeutic agents [1] and is therefore often referred to as the "incurable nightmare" [2]. The treatment of M. abscessus infections usually consists of a mixture of a macrolide plus parenteral antimicrobials, that can be either an aminoglycoside or cefoxitin, imipenem 
or tigecycline [3, 4]. The cure rate achieved among patients with an $M$. abscessus pulmonary infection is typically between 25 and $88 \%$ [5-7], and therapy is usually given for as long as $18-24$ months, with a minimum combination of three drugs $[5,8]$. In addition, these therapeutic schemes have a high cost, it has been estimated that a total of 1.4 billion dollars was spent on NTM-pulmonary disease in the USA in 2014 [9]. Therefore, there is an urgent need to develop safe and more effective drugs with anti-NTM activity. Currently, there are potential therapeutic agents in research and development for the treatment of NTM pulmonary disease, including $M$. abscessus infection. However, with the tuberculosis drug pipeline, where $>35$ chemical entities are in the discovery stage, the NTM drug pipeline is nearly empty [10].

In addition, to develop more effective regimens against NTM diseases, it is necessary to implement models to help test novel drugs or compounds with potential antibiotic effects. The efficacy of drugs against $M$. abscessus, as well as other mycobacteria, is traditionally studied using in vitro and in vivo models [11-13]; however, in vitro studies cannot fully represent the complexity of the lung architecture and its impact on host-pathogen interactions, while animal models have their own limitations $[14,15]$. For example, animal experiments are often poorly designed and fail to provide the proper foundation for subsequent human studies [16], and they have issues related to reproducibility and translation into preclinical studies [17].

The necessity of experimental models that provide a more accurate representation of the in vivo 3D structure of the lung than cell lines, grown as monolayers, has increased the interest in ex vivo tissue cultures [18]. With this approach, tissue explants have been successfully infected with Mycobacterium tuberculosis, M. abscessus, and Mycobacterium avium [19]. Similarly, we have reported a $M$. tuberculosis infection model using precision-cut lung slices (PCLS) [20]. PCLS are an ex vivo system that reflects the 3D tissue architecture, cellular composition, matrix complexity, metabolic function and immune response of the lung [21, 22]. PCLS have also been used as an infection model to study mycoplasma [23], viruses [24, 25] and bacteria [26-28]. The characteristics of this ex vivo lung model system could offer some advantages when testing compounds directed against several pathogens of the respiratory tract.

In this work, we describe the evaluation of an infection model with a virulent strain of $M$. abscessus using murine precision-cut lung tissue slices. Once infection was established, we evaluated the antimicrobial activity of tigecycline and imipenem against the infected lung slices. This model will provide valuable information for the study of
M. abscessus pathogenesis and in the search for novel drugs against mycobacteria.

\section{Materials and methods Bacterial strains}

M. abscessus virulent strain L948 (ATCC 19977) was grown in Middlebrook 7H9 broth and stored in vials at $-70{ }^{\circ} \mathrm{C}$. Bacterial vials were thawed, and the colony forming units $/ \mathrm{mL}(\mathrm{CFU} / \mathrm{mL})$ were determined by serial dilution on blood agar.

\section{Compounds}

Tigecycline and imipenem (PiSA Pharmaceutical, DF, México) were reconstituted in sterile $0.85 \% \mathrm{NaCl}$, and aliquots were prepared and stored at $-70^{\circ} \mathrm{C}$ until further use. Krebs-Henseleit (KB) buffer ( $\mathrm{pH}$ 7.4) was used for PCLS preparation, and DMEM/F12 supplemented with $10 \%$ bovine fetal serum, $1 \%$ insulin-transferrin-selenium and $25 \mathrm{mM}$ glucose (complete medium) was used for PCLS culture.

\section{Minimal inhibitory concentration}

Tigecycline and imipenem stock solutions were prepared at a concentration of $1 \mathrm{mg} / \mathrm{mL}$. The MIC value for each drug against $M$. abscessus L 948 (virulent strain) was determined as recommended by the Clinical and Laboratory Standards Institute (CLSI) document M24-A2 using a broth microdilution method [29]. The final drug concentration range was 0.25 to $64 \mu \mathrm{g} / \mathrm{mL}$. The MIC values were determined after $72 \mathrm{~h}$ of incubation at $30{ }^{\circ} \mathrm{C}$. Quality control testing was performed using Staphylococcus aureus ATCC 29213.

\section{Precision-cut lung tissue slices preparation}

The PCLS were prepared from 8 to 10-week-old male $\mathrm{BALB} / \mathrm{c}$ mice (Harlan Laboratories SA de CV, México). The mice were euthanized with an overdose of sodium pentobarbital $(6 \mathrm{mg} / 100 \mathrm{~g})$ following institutional and international guidelines for the humanitarian care of animals used in experimental work. Afterwards, the pleural cavity was exposed under aseptic conditions, and the trachea was cannulated to infiltrate the lungs with $0.7 \%$ lowgelling temperature agarose in basal DMEM/F12 medium at $37^{\circ} \mathrm{C}$. The lungs were allowed to cool on ice to obtain a firm consistency and were then excised and immersed in sterile Krebs-Henseleit (KB) buffer ( $\mathrm{pH} 7.4$ at $\left.4{ }^{\circ} \mathrm{C}\right)$. Cylindrical lung tissue cores of $5 \mathrm{~mm}$ diameter were obtained; from these, $350-400 \mu \mathrm{m}$ thick tissue slices were prepared using a Krumdieck ${ }^{\circledR}$ tissue slicer (Munford, AL, USA), with a constant flow of oxygenated $\mathrm{KB}$ buffer $\left(4^{\circ} \mathrm{C}\right.$, 95:5\% $\mathrm{O}_{2}: \mathrm{CO}_{2}$ ). The lung slices were placed in 24-well microplates (one per well) with $1 \mathrm{~mL}$ per well of DMEM/ F12 medium. The plates were pre-incubated for $4 \mathrm{~h}$ at 
$37{ }^{\circ} \mathrm{C}, 5 \% \mathrm{CO}_{2}$, with a slow agitation at $\sim 25 \mathrm{rpm}$, and the medium was changed four times every $30 \mathrm{~min}$ to remove the agarose. Afterwards, the basal viability of the lung tissue slices was determined by Alamar Blue ${ }^{\mathrm{TM}}$ assay [30]. Fluorescence (at $530 \mathrm{~nm}$ excitation/590 nm emission wavelengths) was determined in the FLx800 Multi-detection Microplate Reader (Biotek Instruments, Winooski, VT, USA).

\section{Infection of the PCLS and intracellular activity of the antibacterial drugs}

After removing the agarose from the tissue, $250 \mu \mathrm{L}$ of DMEM/F12 complete medium was added to the PCLS in the 24-well microplates and inoculated with $M$. abscessus ATCC 19977 (1.5 × 10 $\mathrm{CFU}$ in total, per slice). One group of slices was processed immediately for histopathological analysis. The remaining slices were inoculated and incubated at $37{ }^{\circ} \mathrm{C}$ with $5 \% \mathrm{CO}_{2}$ for $1 \mathrm{~h}$ without agitation. Then, $1 \mathrm{~mL}$ of complete DMEM/F12 was added, followed by incubation for $1 \mathrm{~h}$. After removing the medium, the slices were washed twice with $500 \mu \mathrm{L}$ of PBS buffer with amikacin $(200 \mu \mathrm{g} / \mathrm{mL})$ to eliminate any extracellular M. abscessus. The PCLS were washed again, and the antimicrobial compounds diluted in complete DMEM/ F12 medium were added by triplicate as follows: imipenem at 4, 16 and $64 \mu \mathrm{g} / \mathrm{mL}$ and tigecycline at $0.25,1$ and $4 \mu \mathrm{g} / \mathrm{mL}$, followed by incubation for 12,24 and $48 \mathrm{~h}$. The CFUs were determined by transferring the PCLS to a microcentrifuge tube containing $1 \mathrm{~mL}$ of distilled water and sterile glass beads and washing twice. The intracellular bacteria were released using a sterile scalpel macerating the tissue until it had disintegrated, followed by vortexing with $1 \mathrm{~mL}$ of PBS-Tween 20 solution for $5 \mathrm{~min}$; CFUs were determined by plating on blood agar. The experiments were performed in triplicate, and the data were expressed as the $\log _{10}$. In all cases, a control group, untreated with antibiotic, was prepared for each corresponding time point.

\section{PCLS histopathological analysis}

After incubation time the infected and control lung tissue slices were fixed in $10 \%$ neutral formalin for $24 \mathrm{~h}$ at room temperature and then embedded in paraffin using conventional histological techniques. Sections of $5 \mu \mathrm{m}$ thickness were obtained from the embedded tissues using a microtome (American Optical, Buffalo NY, USA), mounted on glass slides, and stained with hematoxylin and eosin $(\mathrm{H} \& \mathrm{E})$ or Ziehl-Neelsen $(\mathrm{ZN})$ dyes. The Oil red-O stain kit KTORO (StatLab., McKinney TX, USA) was used to perform the Oil red-O classic lipid stain to confirm the presence of foamy macrophages. Frozeninfected slices were carefully embedded in Tissue-Tek ${ }^{\circledR}$ on the mold of the cryostat. Sections of 10-12 $\mu$ m-thick were prepared using a Leica CM1850 cryostat (Buffalo Grove, IL, USA); they were placed on glass slides and let them dry for $30 \mathrm{~min}$ at room temperature; the staining process was done according to the manufacturer instructions. Briefly: slides with the frozen sections were placed in $10 \%$ neutral formalin for 2-5 min then rinsed in tap water. Slides were subsequently placed in propylene glycol for $2 \mathrm{~min}$, stained 6 min with oil red $\mathrm{O}$ working solution at $60{ }^{\circ} \mathrm{C}$; placed $1 \mathrm{~min}$ in $85 \%$ propylene glycol, rinsed twice with distilled water; stained 1 min with modified Mayer's hematoxylin, rinsed twice with tap water followed by 2 changes of distilled water, and mounted with aqueous glycerol-jelly medium. All the stained sections were observed using a Zeiss Axiostar Plus Brightfield Microscope (Jena, Germany); photographs were obtained with a 5.0 Moticam camera (Richmond, BC, Canada). All sections were observed using a Zeiss Axiostar Plus Brightfield Microscope (Jena, Germany); photographs were obtained with a 5.0 Moticam camera (Richmond, BC, Canada).

\section{Statistical analysis}

For the descriptive analysis, all the values are presented as mean values and standard deviations $( \pm S D)$. The data were compared by using the Student's t-test and Bonferroni's multiple comparison posttest, considering $P<0.05$ as significant.

\section{Results}

PCLS of adequate quality were obtained to perform all the experiments. Lung slices with thickness, diameter, and macroscopic integrity were selected.

\section{Histopathologic analysis}

The morphology of freshly obtained lung tissue showed no differences with the uninfected PCLS incubated for 5 days, based on the histologic structure. Representative images of the cultured PCLS show their characteristic structural elements: typical bronchi, terminal and respiratory bronchioles, alveolar ducts, alveolar sacs, alveoli and septa. In addition to the structural elements, alveolar macrophages, and type I and II pneumocytes were observed (Fig. 1a-d). Thin blood vessels were seen in the alveolar septa, with little to no evidence of inflammatory cells in the alveolar space. After 5 days of incubation, the histologic integrity of the tissue was maintained. The viability of the lung tissue slices was $97 \%$ at $48 \mathrm{~h}$ and there were no significant differences in the viability of the freshly obtained (basal) and control (uninfected) slices ( $100 \pm 5 \%$ and $116 \pm 20 \%$, respectively).

In $M$. abscessus-infected PCLS for six to $24 \mathrm{~h}$, we observed a mixed inflammatory reaction (Fig. 1e-g) mainly composed of abundant foamy macrophages, 

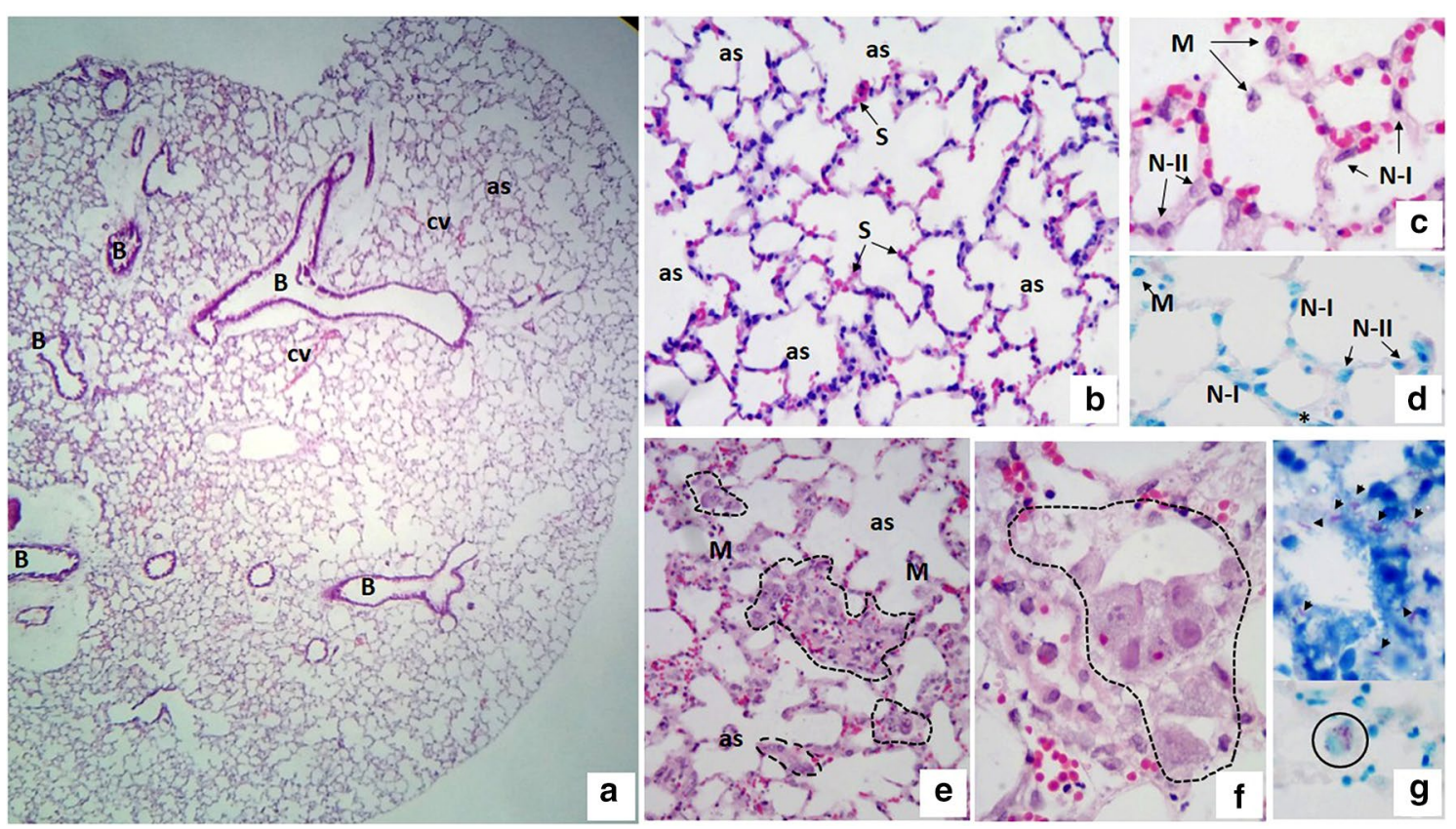

Fig. 1 Uninfected (control) and Mycobacterium abscessus-infected murine precision-cut lung slices. a-c Uninfected PCLS cultured for $48 \mathrm{~h}$ show normal pulmonary histology, with empty alveolar spaces (as) and alveolar septa (S) constituted by fibrous connective tissue and congestive blood vessels. The walls of the septa are lined by type I pneumocytes ( $\mathrm{N}-\mathrm{I})$ and type II pneumocytes ( $\mathrm{N}-\mathrm{II})$. Some isolated macrophages are observed in the wall and in the lumen of the alveolus (M). $\mathbf{d}$ Uninfected PCLS (control), macrophages (M), and type I (NI) and type II (NII) pneumocytes are observed. The ZN staining is negative. e, $\mathbf{f} \mathrm{In}$ PCLS infected with M. abscessus for $24 \mathrm{~h}$, a chronic inflammatory reaction is observed, mainly composed by lymphocytes and foamy macrophages forming conglomerates (dotted area). $\mathbf{g}$ Representative photomicrograph of infected slices stained with ZN that are positive for the presence of mycobacteria; M. abscessus is found in the lumen of the alveoli (arrowheads) and intracellularly infecting the foamy macrophages (circle). H\&E staining: (a-c, e, f), ZN staining: (d, g). Total magnification: $\times 5(\mathbf{a}), \times 10(\mathbf{b}, \mathbf{e}), \times 40(\mathbf{c}, \mathbf{d}, \mathbf{f}, \mathbf{g})$

lymphocytes, and plasmatic cells. Mycobacteria bacilli were found in the PCLS, particularly in the alveolar lumen, in close contact with the foamy macrophages, or intracellularly infecting these cells. At $6 \mathrm{~h}$ post-infection, the presence of a greater number of epithelioid cells in the alveoli, a few lymphocytes in the septa, and some septa with mild edema were observed, while the histologic architecture was still conserved. After 12 and $24 \mathrm{~h}$ post-infection, the alveolar septa showed more edema, vascular congestion, and extravasation of erythrocytes and lymphocytes in the septa and the alveolar spaces (Fig. 1e-g).

After $48 \mathrm{~h}$ of incubation with the mycobacteria (Fig. 2), we observed damage in the histologic structure: inflammatory infiltrates composed of histiocytes and aggregates of foamy macrophages, as well as nuclear fragmentation of the PMN cells ("nuclear dust"). Rupture of the alveolar septa, vascular congestion and thickening of the alveolar septa in other areas were also noticed (Fig. $2 \mathrm{a}-\mathrm{g}$ ). Some of the foamy macrophages presented nuclear changes, such as pyknosis, karyolysis and karyorrhexis (Fig. 2). Abundant mycobacteria were observed in the alveolar septum infecting the type II pneumocytes and in the areas of confluence of foamy macrophages (Fig. 2). Langhans multinucleated cells were also observed (Fig. 2e, g); mycobacterial fragments inside the multinucleated giant cells were sometimes observed.

The interactions of $M$. abscessus with inflammatory cells and pneumocytes in the alveolar septa are shown in Fig. 3a-f. M. abscessus interacts directly with type I and type II pneumocytes, neutrophils, lymphocytes, and macrophages. Bacilli were observed isolated in the alveoli and alveolar space but also with a tendency to form aggregates in the alveolar septum, near to or in close contact with the epithelial cells; they were also found between cellular debris in areas of inflammation and in close contact with macrophages. We observed the infection of macrophages and type I pneumocytes, as bacilli were seen inside of these cells. Foamy macrophages filled with lipid-containing bodies were frequently found in frozen sections from infected PCLS stained with Oil red-O (Fig. 4).

To confirm the usefulness of this model, we studied the intracellular effect of imipenem and tigecycline on the infected PCLS. The MIC values for tigecycline and imipenem were 1 and $16 \mu \mathrm{g} / \mathrm{mL}$, respectively, for this $M$. 


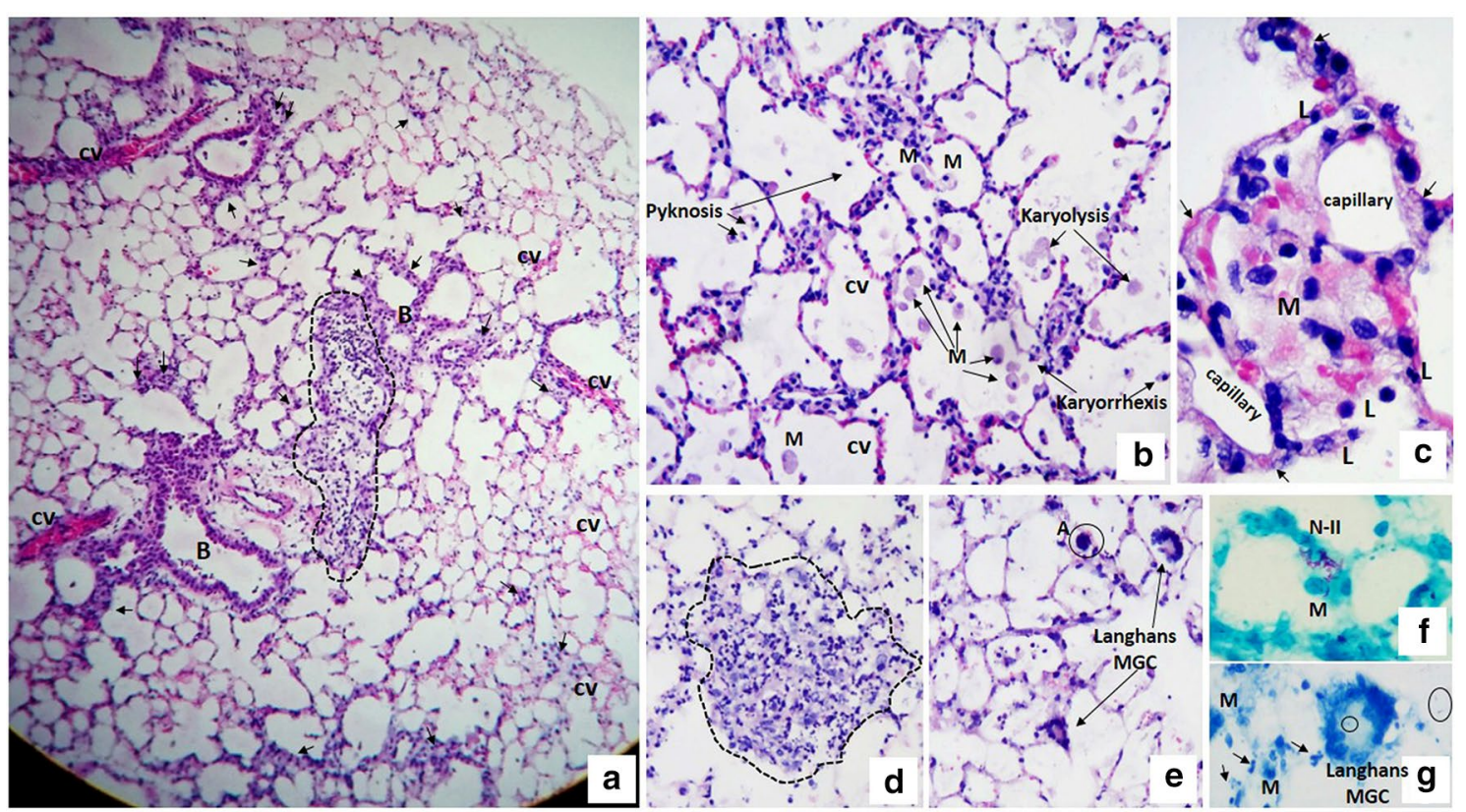

Fig. 2 Morphological aspects of the infection of murine PCLS infected for $48 \mathrm{~h}$ with M. abscessus. a Panoramic view of a complete lung slice infected with M. abscessus for $48 \mathrm{~h}$ showing preserved tissue viability and an inflammatory aggregate with a loss of alveolar spaces (dotted area). Vascular congestion (vc) and discrete inflammatory infiltrate in the peribronchioles (B) with septal thickening (arrowhead) are also observed. $\mathbf{b}$ Alveolar spaces with an increase in foamy macrophages (FM), some of which show nuclear changes such as pyknosis, karyolysis and karyorrhexis. In the alveolar septa, vascular congestion and moderate inflammatory infiltrate are observed. c The alveolar space is occupied entirely by a conglomerate of foamy macrophages mixed with erythrocytes; the alveolar septa show discrete thickening secondary to edema, vascular congestion (arrows) and lymphocyte infiltrate (L). In addition, normal capillary vessels are observed adjacent to the septa. $\mathbf{d}$, e Photomicrograph showing lung tissue with a loss of its histological structure and occupied by inflammatory infiltrates of mononuclear cells, polymorphonuclear cells, and histiocyte/macrophages (dotted area). The rest of the tissue shows septal inflammation and vascular congestion. In addition to the histological findings in the photomicrograph (c), multinucleated giant Langhans cells and apoptotic cells (A) are observed. f Abundant mycobacteria in the alveolar septum infecting type II pneumocytes (N-II) and foamy macrophages (FM). g Mycobacterial fragments (circles) are observed within Langhans multinucleated giant cell and extracellularly. Foamy macrophages (FM) and nuclear fragments (arrows) can also be observed. H\&E staining $(\mathbf{a}-\mathbf{e})$. ZN staining $(\mathbf{f}, \mathbf{g})$. Total magnification: $\times 50(\mathbf{a}), \times 100(\mathbf{d}, \mathbf{e}), \times 200(\mathbf{b}), \times 400(\mathbf{c}, \mathbf{f}, \mathbf{g})$

abscessus strain. Bactericidal activity and bacteriostatic activity were defined as $\geq 3 \log _{10}$ and $<3 \log _{10}$ reduction of total count of $\mathrm{CFU} / \mathrm{mL}$, respectively, in comparison with the initial inoculum after 12, 24, 36 and $48 \mathrm{~h}$ of incubation according to standard guides [31]. Bacteriostatic intracellular activity on the infected slices was observed with imipenem. As shown in Fig. 5, the intracellular CFU count decreased only $1 \log$ at $48 \mathrm{~h}$ at the highest drug concentration used. A Student's t-test showed no significant difference between the imipenem-treated slices and the nontreated control.

A better result was obtained with tigecycline, which showed a dose-and time-dependent activity and a bactericidal effect at $48 \mathrm{~h}$ that reached a reduction of $>4 \log _{10} \mathrm{CFU} / \mathrm{mL}$ (Fig. 5). A post hoc test showed a statistically significant difference between the control and those slices treated with tigecycline at $1 \times$ and $4 \times$ the MIC $(\mathrm{P}<0.05)$.

We also corroborated that intracellular bacteria recovered from the infected PCLS at equivalent time points were viable $M$. abscessus by lysing and plating the tissue homogenate in blood agar, as described in "Materials and methods" section. After incubation, the growth of round bacterial colonies with the typical morphology of mycobacteria was observed (Fig. 6a). The subsequent $\mathrm{ZN}$ staining of the smears from these colonies showed the presence of the mycobacterial bacilli (Fig. 6b). These results and the previously described morphological findings support the utility of the experimental infection model.

\section{Discussion}

Due to the antimicrobial resistance shown by $M$. abscessus, it is necessary to study and analyze new antibacterial candidates using physiologically relevant models. Here, we evaluated a preclinical model for $M$. abscessus infection using PCLS and validated it by determining the antimicrobial effects of imipenem and tigecycline. A stable and sustained growth of the bacteria was observed inside 



Fig. 3 Interactions of M. abscessus with epithelial cells in the infected PCLS. a-c M. abscessus, stained in pink, can be found isolated or forming aggregates in the alveolar space; mycobacteria can be observed interacting directly with type I pneumocytes (NI), type II pneumocytes (N-II), neutrophils $(N)$, lymphocytes $(L)$, and foamy macrophages $(F M)$, some of which demonstrate karyorrhexis $\left(M^{*}\right)$; in addition, cell detritus with nuclear fragments are observed (dotted area in $\mathbf{c}$ ). $\mathbf{d}$ A cluster of foamy macrophages (dotted area), some of which show nuclear pyknosis (P); mycobacterial fragments are identified with arrows. e, f Multinucleated giant cell (MGC) interacting with mycobacteria (arrows). ZN staining ( $\times 40)$. Total magnification

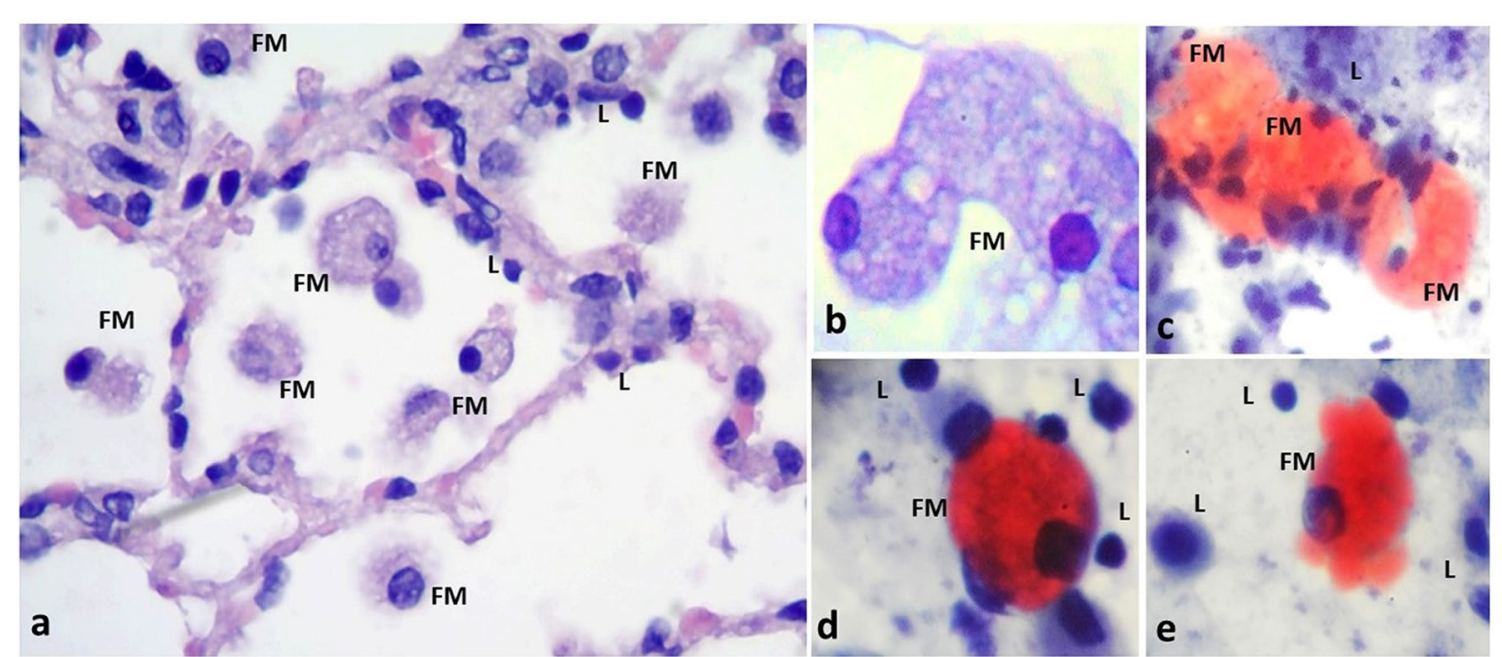

Fig. 4 Presence of foamy macrophages in the infected PCLS. Inflammatory infiltrates with aggregates of foamy macrophages were frequently observed in the PCLS infected with M. abscessus. a Alveolar spaces with abundant foamy macrophages (FM). b Cellular detail of FM containing multiple intracytoplasmic vacuoles. Foamy macrophages (FM) can be found in aggregates (c), or isolated (d, e), with positive staining for accumulation of lipids in their cytoplasm; lipid-laden cells are a distinctive hallmark of mycobacterial infections. Mononuclear cells, predominantly lymphocyes $(L)$ are also observed. H\&E staining $(\mathbf{a}, \mathbf{b})$. Oil red-O staining $(\mathbf{c}-\mathbf{e})$. Total magnification: $\times 10(\mathbf{a}), \times 40(\mathbf{b}-\mathbf{e})$ 

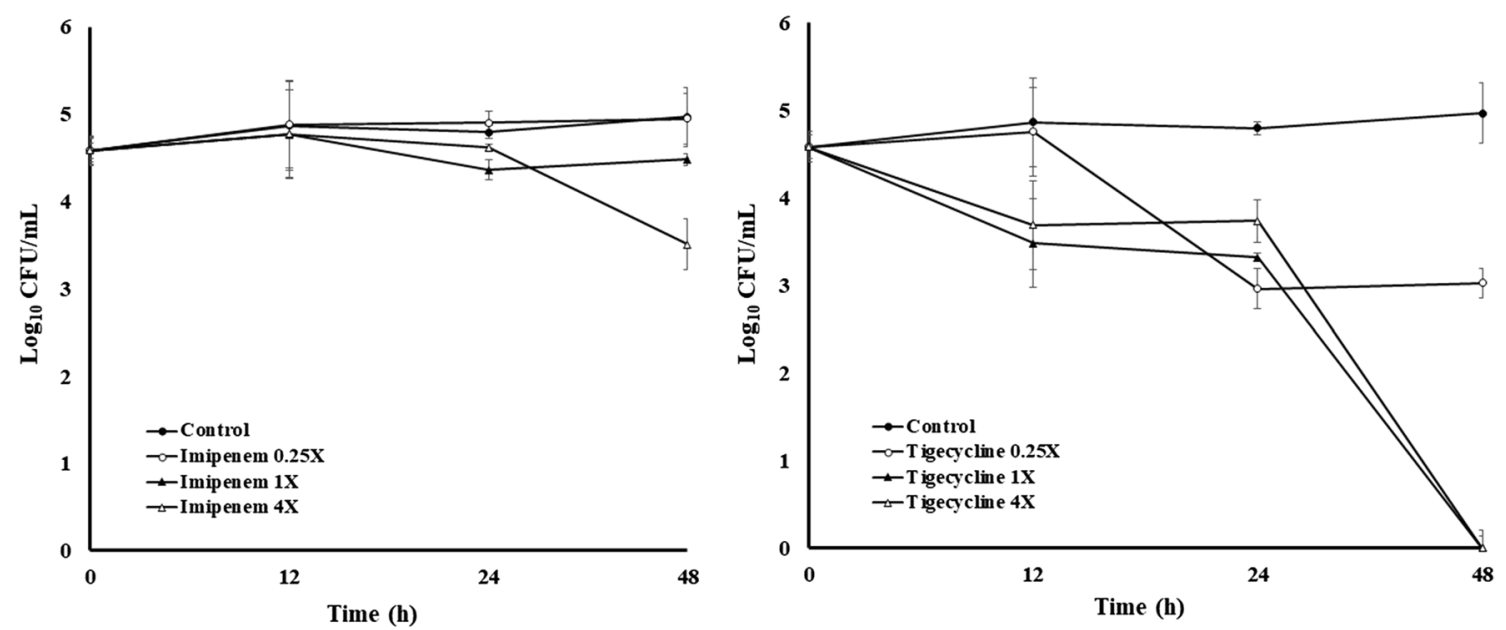

Fig. 5 Intracellular activity of antimicrobials in M. abscessus-infected murine lung slices. Bacterial counts were performed at 12, 24, and 48 h after infection. Error bars represents the mean of three measurements
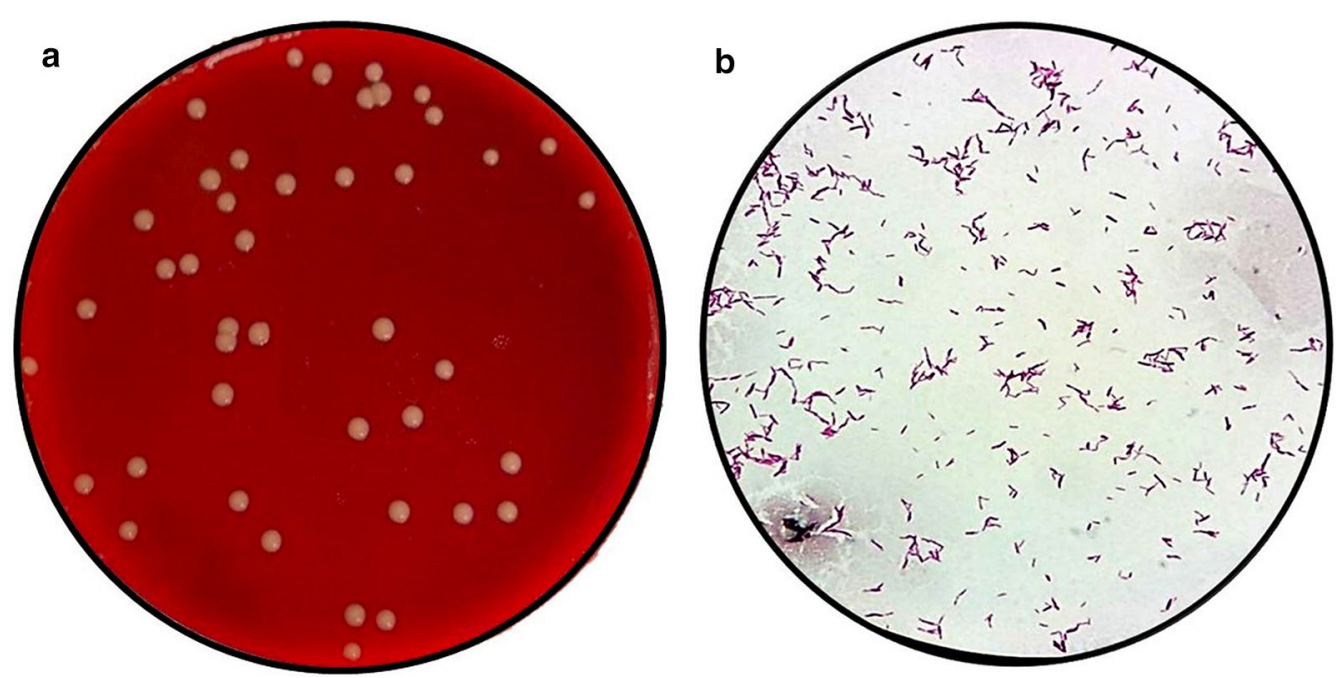

Fig. 6 Culture of the lysates from PCLS infected with M. abscessus. a Typical colony morphology of mycobacteria from the culture of the lysate of murine lung slices infected with M. abscessus. b Microscopic morphology of acid-resistant acid bacilli from the same bacterial colonies (arrowheads). ZN staining $(\times 100)$

the tissue up to $48 \mathrm{~h}$ post-infection, allowing us to assess the antimicrobial activity of these drugs.

Other approaches to study the intracellular activity of drugs against $M$. abscessus have been performed in vitro using a variety of macrophages, including bone marrowderived macrophage, J774 and THP-1 cells [32-34].

Animal models have also been used to evaluate the antimycobacterial efficacy of drugs against $M$. abscessus infection; however, only severely immunocompromised strains of mice such as GKO or SCID have shown acceptable levels of infection [35-37]. The advantage of these mouse models is that $M$. abscessus progressively develops a high level of infection, allowing the detection of significant differences between the $M$. abscessus control and the drug-treated groups [35].

Nevertheless, in vivo studies have sometimes led to inconsistent results [10]; for instance, bedaquiline treatment reduced the CFUs by 2 logs in a SCID mouse model but was almost inactive in nude mice [35, 37]. However, the main limitations of animal models in the search for antimicrobial activity against NTM are the large number of experimental animals regularly used, and the high 
costs of housing and handling the genetically modified mice $[35,38,39]$.

Additionally, it has been reported that it takes up to 60 days for the study of the infection using the C57BL/6 and GKO mice [36]. These facts contrast sharply with the number of animals used in the present work and the time taken; here we used only ten mice, including those used for standardization, and the ex vivo time course of infection induced by $M$. abscessus was only a few days. In contrast, we were able to observe the histopathological characteristics of $M$. abscessus-induced damage and the pathogen's interactions with lung parenchyma cells after a short time post-infection $(6-48 \mathrm{~h})$, while animal models need 10 to 60 days to develop lung damage [35, 36, $38,40]$. Studies with $M$. tuberculosis $[19,20]$ and other pathogens [41-45] using PCLS or tissue explants, where tissue lesions or inflammatory infiltrates are observed at 24-48 $\mathrm{h}$ post-infection, support the advantage of these ex vivo models.

Findings such as the presence of foamy macrophages or nuclear fragmentation of neutrophils seen before $24 \mathrm{~h}$ in our model corroborate those results reported by Bernut et al. [46] who described the same results using zebrafish embryos.

At $48 \mathrm{~h}$ post-infection, we observed the presence of Langhans cells, which have not been previously reported in murine models of M. abscessus infection. These multinucleated giant cells are a histopathological landmark for mycobacterial infections, where they seem to have an important role in restricting mycobacterial growth [47, 48], although they are not specific, as they are also present in numerous granulomatous diseases [49], including those caused by nontuberculous mycobacteria [50, 51]. Langhans cells have been reported in granulomatous infiltrates in $M$. abscessus-induced cutaneous and pulmonary infections in immunocompromised patients [52-55].

At the histopathological level, in one of the most extensive studies where nine different transgenic murine models were used to analyze the ability of $M$. abscessus to induce infection, granuloma formation was reported, but multinucleated giant cells were not seen [35]. In contrast, granulomas with Langhans multinucleated cells were found in $B A L B / c$ infected with the vaccine strain of $M$. bovis (the Bacillus Calmette-Guérin vaccine, BCG1). However, the granulomas containing these multinucleated Langhans cells were obtained from splenic tissues but not from the lungs of the infected mice [56]. In general terms, the histopathological findings that we describe here are akin to those reported by other investigators [35, 36, 40, 57].

Ordway et al. [36] infected knockout mice with a high-dose aerosol of $M$. abscessus, and demonstrated peribronchiolar inflammatory infiltrates at 15 days; at day 30 , they observed granulomas composed of aggregates of lymphocytes and foamy cells; and by day 60 , the granulomas were larger, as well as the inflammatory infiltrates. When guinea pigs were infected in the same way, a more severe granulomatous inflammation in the lungs was observed at day 60 , and it was characterized by sheets of epithelioid macrophages and organized aggregates of lymphocytes that infiltrated septal walls and filled alveolar spaces.

De Groote et al. [57] developed an animal model of $M$. abscessus chronic infection using granulocyte-macrophage colony-stimulating factor knockout (GM-CSF KO) mice. They reported inflammation of the bronchioles and alveolar architecture alterations in infected animals, with presence of macrophages and neutrophils. Acid-fast bacilli were observed inside macrophages, as well as some free bacilli in alveoli too, and after 4-months of chronic infection, large accumulations of foamy macrophages within the alveoli were observed.

In our PCLS model, the uninfected slices kept their tissue architecture intact, while the histological analysis of PCLS infected with M. abscessus showed the presence of polymorphonuclear cells, epithelioid cells, foamy macrophages, multinucleated giant cells, and the signs of an early granulomatous inflammation after 6 and $12 \mathrm{~h}$ post-infection. We also observed acid-fast bacilli within macrophages, and isolated bacillus or forming aggregates in the alveolar spaces. The infected PCLS showed tissue destruction, causing the loss of the histological architecture, rupture of the alveolar septa, and areas of inflammatory aggregates with nuclear PMN fragmentation, as well as vascular congestion and thickening of the alveolar septa at $48 \mathrm{~h}$ post infection. The histological changes found in the in vivo models are similar to those found in the BALB/c mice PCLS model infected with $M$. abscessus, but at shorter infection time and it indicates that our model responds in a very similar way as the lung tissue does in an animal model.

An additional advantage of the ex vivo infection model using PCLS is that we used normal BALB/c mice, while murine infection models to study $M$. abscessus require expensive genetically modified mice, thus our methodology decreases the cost per experiment.

The development of our ex vivo 3D model enables the study of an $M$. abscessus experimental infection within a physiological milieu and provides the opportunity to study the infection process not only in lung tissue from laboratory animals but also in human lung tissue, as reported by Ganbat et al. [19] who used a similar ex vivo tissue culture model for mycobacterial infections. These authors infected the human lung tissues samples with two strains of each three different mycobacterial species, 
including $M$. abscessus, and focused on the very early onset of TB infection, and on the specific interactions between mycobacteria and the cells of the lung. The morphologic comparisons between freshly obtained and cultured ex vivo lung specimens showed no noticeable differences, like our results. The authors found, as we also did, that mycobacteria can infect different cell types, including macrophages, neutrophils, monocytes, and type II pneumocytes.

The presence of foamy macrophages in PCLS infected with M. abscessus was clearly demonstrated (Fig. 4). Foamy macrophages are a distinctive characteristic of granulomas associated with virulent mycobacteria; these cells have been observed in different inflammatory conditions, including infectious and noninfectious diseases, such as natural and experimental TB in particular [58]. The formation of foamy macrophages has been described in models of infection with $M$. abscessus both, in vitro $[59,60]$, and in vivo $[61,62]$. It has been suggested that the induction of foamy macrophages results in an intracellular microenvironment that allows the persistence of mycobacteria, and that the fatty acids that accumulated in their cytoplasmic vacuoles represent a source of nutrients for the bacilli [63].

Our findings on the ability of $M$. abscessus to infect lung cells in PCLS allowed us to evaluate the effects of two well-known antibacterial drugs. Imipenem, an antibiotic that is part of the multidrug therapy recommended for infections by $M$. abscessus, showed little effect against bacteria at a low MIC concentration, but a bacteriostatic effect at medium and high concentrations. This was an expected result, as other studies have shown the same behavior when intracellular activity was investigated [32, 64]. We also evaluated tigecycline, which has previously demonstrated good in vitro MICs against $M$. abscessus isolates and has been used as a rescue treatment for M. abscessus and Mycobacterium chelonae complicated infections [8]. In this study, tigecycline was bactericidal after 24 and $48 \mathrm{~h}$ post-infection at $1 \times$ and $4 \times$ the MIC value $(\mathrm{P}<0.05)$. Previously, this compound had already been demonstrated to have an observable bactericidal effect against resistant $M$. abscessus in a hollow-fiber model system for pulmonary disease [65], as well as intracellular activity in a THP-1 macrophage model [32].

\section{Conclusions}

In conclusion, PCLS represent a useful 3D model for the study of ex vivo infection with $M$. abscessus and the activity of new antimycobacterial drugs. This model has the simplicity and reproducibility of in vitro models, but its major advantage is the presence of more than forty differentiated cell types with metabolic capability, polarization, and extracellular elements found in in vivo models.
Furthermore, this model complies with the 3R's Principle $[66,67]$ and provides the opportunity for testing new drugs against $M$. abscessus, decreasing the use of costly and tedious animal models.

\section{Abbreviations \\ TB: Tuberculosis; PCLS: Precision cut lung slices; NTM: Nontuberculous myco- bacteria; CFU/mL: Colony forming units/mL; MIC: Minimal inhibitory concen- tration; CLSI: Clinical and Laboratory Standards Institute; ZN: Ziehl-Neelsen; H\&E: Hematoxylin and eosin.}

\section{Acknowledgements}

We thank QBP Consuelo Coronado-Martínez for technical assistance.

\section{Authors' contributions}

CAMT and PCR conceived and designed the experiments; ONFC and IECT performed experiments; EVV drafted the original manuscript and performed statistical analysis; NEGD performed the histopathological análisis; LVC, JOC, JVS and JCG supervised the experiments and participated in the interpretation of data, wrote or helped to draft the manuscript. All authors read and approved the final manuscript.

\section{Funding}

Not applicable.

\section{Availability of data and materials}

The datasets used and/or analyzed during the current study are available from the corresponding author on reasonable request.

\section{Ethics approval and consent to participate}

The study protocol was approved (Approval: CNIC-IMSS 1908/2005/004) by the National Committee for Scientific Research from the Instituto Mexicano del Seguro Social (IMSS).

\section{Consent for publication}

Not applicable.

\section{Competing interests}

The authors declare that they have no competing interests.

\section{Author details}

1 Servicio de Dermatología, Hospital Universitario "José E. González", Universidad Autónoma de Nuevo León, Monterrey, NL, México. ${ }^{2}$ Facultad de Ciencias Biológicas, Universidad Autónoma de Nuevo León, Monterrey, NL, México. ${ }^{3}$ Centro de Investigación Biomédica del Noreste, Instituto Mexicano del Seguro Social, Monterrey, NL, México. ${ }^{4}$ División de Investigación en Salud, UMAE, Hospital de Cardiología \#34, Instituto Mexicano del Seguro Social, Monterrey, NL, México.

Received: 22 December 2019 Accepted: 12 November 2020

Published online: 22 November 2020

\section{References}

1. Brown-Elliott BA, Wallace RJ Jr. Clinical and taxonomic status of pathogenic nonpigmented or late-pigmenting rapidly growing mycobacteria. Clin Microbiol Rev. 2002;15(4):716-46.

2. Nessar R, Cambau E, Reyrat JM, Murray A, Gicquel B. Mycobacterium abscessus: a new antibiotic nightmare. J Antimicrob Chemother. 2012;67(4):810-8.

3. Griffith DE, Aksamit T, Brown-Elliott BA, Catanzaro A, Daley C, Gordin F, et al. An official ATS/IDSA statement: diagnosis, treatment, and prevention of nontuberculous mycobacterial diseases. Am J Respir Crit Care Med. 2007;175(4):367-416.

4. Haworth CS, Banks J, Capstick T, Fisher AJ, Gorsuch T, Laurenson IF, et al. British Thoracic Society guidelines for the management of 
non-tuberculous mycobacterial pulmonary disease (NTM-PD). Thorax. 2017;72(Suppl 2):ii1-64.

5. Jeon K, Kwon OJ, Lee NY, Kim BJ, Kook YH, Lee SH, et al. Antibiotic treatment of Mycobacterium abscessus lung disease: a retrospective analysis of 65 patients. Am J Respir Crit Care Med. 2009;180(9):896-902.

6. Jarand J, Levin A, Zhang L, Huitt G, Mitchell JD, Daley CL. Clinical and microbiologic outcomes in patients receiving treatment for Mycobacterium abscessus pulmonary disease. Clin Infect Dis. 2011;52(5):565-71.

7. Koh WJ, Jeong BH, Kim SY, Jeon K, Park KU, Jhun BW, et al. Mycobacterial characteristics and treatment outcomes in Mycobacterium abscessus lung disease. Clin Infect Dis. 2017;64(3):309-16.

8. Wallace RJ Jr, Brown-Elliott BA, McNulty S, Philley JV, Killingley J, Wilson RW, et al. Macrolide/azalide therapy for nodular/bronchiectatic Mycobacterium avium complex lung disease. Chest. 2014;146(2):276-82.

9. Strollo SE, Adjemian J, Adjemian MK, Prevots DR. The burden of pulmonary nontuberculous mycobacterial disease in the United States. Ann Am Thorac Soc. 2015;12(10):1458-64.

10. Wu ML, Aziz DB, Dartois V, DickT. NTM drug discovery: status, gaps and the way forward. Drug Discov Today. 2018;23(8):1502-19.

11. Pandya AN, Prathipati PK, Hegde P, Li W, Graham KF, Mandal S, et al. Indole-2-carboxamides are active against an acute Mycobacterium abscessus infected mouse model. Antimicrob Agents Chemother. 2019;63(3):e02245-e2318

12. Woo M, Wood C, Kwon D, Park KP, Fejer G, Delorme V. Mycobacterium tuberculosis infection and innate responses in a new model of lung alveolar macrophages. Front Immunol. 2018;9:438.

13. Lefebvre AL, Le Moigne V, Bernut A, Veckerlé C, Compain F, Herrmann JL, et al. Inhibition of the $\beta$-lactamase $B a_{M a b}$ by avibactam improves the in vitro and in vivo efficacy of imipenem against Mycobacterium abscessus. Antimicrob Agents Chemother. 2017;61 (4):e02440-e2516.

14. Berube BJ, Castro L, Russell D, Ovechkina Y, Parish T. Novel screen to assess bactericidal activity of compounds against non-replicating Mycobacterium abscessus. Front Microbiol. 2018;9:2417.

15. Maertzdorf J, Tönnies M, Lozza L, Schommer-Leitner S, Mollenkopf H, Bauer TT, Kaufmann SHE. Mycobacterium tuberculosis invasion of the human lung: first contact. Front Immunol. 2018;9:1346.

16. Giles J. Animal experiments under fire for poor design. Nature 2006:444(7122):981.

17. National Academies of Sciences, Engineering, and Medicine. Advancing disease modeling in animal-based research in support of precision. In: Medicine: proceedings of a workshop. Washington, DC: The National Academies Press; 2018.

18. Cousens C, Alleaume C, Bijsmans E, Martineau HM, Finlayson J, Dagleish MP, Griffiths DJ. Jaagsiekte sheep retrovirus infection of lung slice cultures. Retrovirology. 2015;12:31.

19. Ganbat D, Seehase S, Richter E, Vollmer E, Reiling N, Fellenberg K, et al. Mycobacteria infect different cell types in the human lung and cause species dependent cellular changes in infected cells. BMC Pulm Med. 2016;16:19

20. Carranza-Rosales P, Carranza-Torres IE, Guzmán-Delgado NE, LozanoGarza G, Villarreal-Treviño L, Molina-Torres C, et al. Modeling tuberculosis pathogenesis through ex vivo lung tissue infection. Tuberculosis. 2017:107:126-32.

21. Liu R, An L, Liu G, Li X, Tang W, Chen X. Mouse lung slices: an ex vivo model for the evaluation of antiviral and anti-inflammatory agents against influenza viruses. Antiviral Res. 2015;120:101-11.

22. Temann A, Golovina T, Neuhaus V, Thompson C, Chichester JA, Braun A, Yusibov $V$. Evaluation of inflammatory and immune responses in longterm cultured human precision-cut lung slices. Hum Vaccines Immunother. 2017:13(2):351-8.

23. Weldearegay YB, Müller S, Hänske J, Schulze A, Kostka A, Rüger N, et al. Host-pathogen interactions of Mycoplasma mycoides in caprine and bovine precision-cut lung slices (PCLS) models. Pathogens. 2019;8(2):e82.

24. Krimmling T, Schwegmann-Weßels C. Comparison of mono- and coinfection by swine influenza A viruses and porcine respiratory coronavirus in porcine precision-cut lung slices. Res Vet Sci. 2017;115:470-7.

25. Fu Y, Tong J, Meng F, Hoeltig D, Liu G, Yin X, Herrler G. Ciliostasis of airway epithelial cells facilitates influenza A virus infection. Vet Res. 2018;49(1):65

26. Graham JG, Winchell CG, Kurten RC, Voth DE. Development of an ex vivo tissue platform to study the human lung response to Coxiella burnetii. Infect Immun. 2016:84(5):1438-45.
27. Meng F, Wu NH, Nerlich A, Herrler G, Valentin-Weigand P, Seitz M. Dynamic virus-bacterium interactions in a porcine precision-cut lung slice coinfection model: swine influenza virus paves the way for Streptococcus suis infection in a two-step process. Infect Immun. 2015;83(7):2806-15.

28. Ebsen M, Mogilevski G, Anhenn O, Maiworm V, Theegarten D, Schwarze J, Morgenroth K. Infection of murine precision cut lung slices (PCLS) with respiratory syncytial virus (RSV) and Chlamydophila pneumoniae using the Krumdieck technique. Pathol Res Pract. 2002:198(11):747-53.

29. Clinical and Laboratory Standards Institute. Susceptibility testing of mycobacteria, nocardiae, and other aerobic actinomycetes; approved standard. 2nd ed. CLSI document M24:A2. Wayne: Clinical and Laboratory Standards Institute; 2011

30. Pirnia F, Frese S, Gloor B, Hotz MA, Luethi A, Gugger M, et al. Ex vivo assessment of chemotherapy-induced apoptosis and associated molecular changes in patient tumor samples. Anticancer Res. 2006;26(3A):1765-72.

31. Clinical and Laboratory Standards Institute. Methods for determining bactericidal activity of antimicrobial agents; approved guidelines M26-A. Wayne: CLSI; 1999.

32. Molina-Torres CA, Tamez-Peña L, Castro-Garza J, Ocampo-Candiani J, Vera-Cabrera L. Evaluation of the intracellular activity of drugs against Mycobacterium abscessus using a THP-1 macrophage model. J Microbiol Methods. 2018;148:29-32.

33. Howard ST, Rhoades E, Recht J, Pang X, Alsup A, Kolter R, Byrd TF. Spontaneous reversion of Mycobacterium abscessus from a smooth to a rough morphotype is associated with reduced expression of glycopeptidolipid and reacquisition of an invasive phenotype. Microbiology. 2006;152(6):1581-90.

34. Greendyke R, Byrd TF. Differential antibiotic susceptibility of Mycobacterium abscessus variants in biofilms and macrophages compared to that of planktonic bacteria. Antimicrob Agents Chemother. 2008;52(6):2019-26.

35. Obregón-Henao A, Arnett KA, Henao-Tamayo M, Massoudi L, Creissen E, Andries $\mathrm{K}$, et al. Susceptibility of Mycobacterium abscessus to antimycobacterial drugs in preclinical models. Antimicrob Agents Chemother. 2015:59(11):6904-12.

36. Ordway D, Henao-Tamayo M, Smith E, Shanley C, Harton M, Troudt J, et al. Animal model of Mycobacterium abscessus lung infection. J Leukoc Biol. 2008;83(6):1502-11.

37. Lerat I, Cambau E, Roth Dit Bettoni R, Gaillard JL, Jarlier V, Truffot C, Veziris $\mathrm{N}$. In vivo evaluation of antibiotic activity against Mycobacterium abscessus. J Infect Dis. 2014;209(6):905-12.

38. Byrd TF, Lyons CR. Preliminary characterization of a Mycobacterium abscessus mutant in human and murine models of infection. Infect Immun. 1999;67(9):4700-7.

39. Caverly LJ, Caceres SM, Fratelli C, Happoldt C, Kidwell KM, Malcolm KC, et al. Mycobacterium abscessus morphotype comparison in a murine model. PLoS ONE. 2015;10(2):e0117657.

40. Lee JY, Lee MS, Kim DJ, Yang SJ, Lee SJ, Noh EJ, et al. Nucleotide-binding oligomerization domain 2 contributes to limiting growth of Mycobacterium abscessus in the lung of mice by regulating cytokines and nitric oxide production. Front Immunol. 2017:8:1477.

41. Rupp J, Droemann D, Goldmann T, Zabel P, Solbach W, Vollmer E, et al. Alveolar epithelial cells type II are major target cells for C. pneumoniae in chronic but not in acute respiratory infection. FEMS Immunol Med Microbiol. 2004;41(3):197-203.

42. Drömann D, Rupp J, Rohmann K, Osbah S, Ulmer AJ, Marwitz S, et al. The TGF-beta-pseudoreceptor BAMBI is strongly expressed in COPD lungs and regulated by nontypeable Haemophilus influenzae. Respir Res. 2010;11:67.

43. Szymanski KV, Toennies M, Becher A, Fatykhova D, N'Guessan PD, Gutbier $B$, et al. Streptococcus pneumoniae-induced regulation of cyclooxygenase-2 in human lung tissue. Eur Respir J. 2012;40(6):1458-67.

44. Harrison F, Muruli A, Higgins S, Diggle SP. Development of an exvivo porcine lung model for studying growth, virulence, and signaling of Pseudomonas aeruginosa. Infect Immun. 2014;82(8):3312-23.

45. Jäger J, Marwitz S, Tiefenau J, Rasch J, Shevchuk O, Kugler C, et al. Human lung tissue explants reveal novel interactions during Legionella pneumophila infections. Infect Immun. 2014;82(1):275-85.

46. Bernut A, Nguyen-Chi M, Halloum I, Herrmann JL, Lutfalla G, Kremer L. Mycobacterium abscessus-induced granuloma formation is strictly 
dependent on TNF signaling and neutrophil trafficking. PLoS Pathog. 2016;12(11):e1005986.

47. Lay G, Poquet Y, Salek-Peyron P, Puissegur MP, Botanch C, Bon H, et al. Langhans giant cells from M. tuberculosis-induced human granulomas cannot mediate mycobacterial uptake. J Pathol. 2007;211(1):76-85.

48. Byrd TF. Multinucleated giant cell formation induced by IFN- $\gamma / \mathrm{LL}-3$ is associated with restriction of virulent Mycobacterium tuberculosis cell to cell invasion in human monocyte monolayers. Cell Immunol. 1998;188(2):89-96.

49. Kumar NS, Prasad TS, Narayan PA, Muruganandhan J. Granuloma with Langhans giant cells: an overview. J Oral Maxillofac Pathol. 2013;17(3):420-3.

50. Merckx JJ, Soule EH, Karlson AG. The histopathology of lesions caused by infection with unclassified acid-fast bacteria in man. Report of 25 cases. Am J Clin Pathol. 1964;41:244-55.

51. Mukhopadhyay S, Gal AA. Granulomatous lung disease. An approach to the differential diagnosis. Arch Pathol Lab Med. 2010;134(5):667-90.

52. Chan WS, Tee SI, Chandran NS, Pan JY. Two episodes of cutaneous nontuberculous mycobacterial infection in a patient with psoriasis. Dermatol Rep. 2015;7(2):5712.

53. Fowler J, Mahlen SD. Localized cutaneous infections in immunocompetent individuals due to rapidly growing mycobacteria. Arch Pathol Lab Med. 2014;138(8):1106-9.

54. Garg P. Nontuberculous mycobacteria in fistula-in-ano: a new finding and its implications. Int J Mycobacteriol. 2016;5(3):276-9.

55. Cullen AR, Cannon CL, Mark EJ, Colin AA. Mycobacterium abscessus infection in cystic fibrosis colonization or infection? Am J Respir Crit Care Med. 2000;161(2):641-5.

56. Ufimtseva E. Mycobacterium-host cell relationships in granulomatous lesions in a mouse model of latent tuberculosis. Biomed Res Int. 2015;2015:948131.

57. De Groote MA, Johnson L, Podell B, Brooks E, Basaraba R, GonzalezJuarrero M. GM-CSF knockout mice for preclinical testing of agents with antimicrobial activity against Mycobacterium abscessus. J Antimicrob Chemother. 2014;69(4):1057-64.

58. Neyrolles O. Mycobacteria and the greasy macrophage: getting fat and frustrated. Infect Immun. 2014;82(2):472-5.
59. Je S, Quan H, Na Y, Cho SN, Kim BJ, Seok SH. An in vitro model of granuloma-like cell aggregates substantiates early host immune responses against Mycobacterium massiliense infection. Biol Open. 2016;5(8):1118-27.

60. Viljoen A, Blaise M, de Chastellier C, Kremer L. MAB_3551c encodes the primary triacylglycerol synthase involved in lipid accumulation in $\mathrm{MycO}$ bacterium abscessus. Mol Microbiol. 2016;102(4):611-27.

61. Maggioncalda EC, Story-Roller E, Mylius J, Illei P, Basaraba RJ, Lamichhane G. A mouse model of pulmonary Mycobacteroides abscessus infection. Sci Rep. 2020;10(1):3690.

62. Riva C, Tortoli E, Cugnata F, Sanvito F, Esposito A, Rossi M, et al. A new model of chronic Mycobacterium abscessus lung infection in immunocompetent mice. Int J Mol Sci. 2020;21(18):E6590.

63. Peyron P, Vaubourgeix J, Poquet Y, Levillain F, Botanch C, Bardou F, et al. Foamy macrophages from tuberculous patients' granulomas constitute a nutrient-rich reservoir for M. tuberculosis persistence. PLoS Pathog. 2008;4(11):e1000204.

64. Lefebvre AL, Dubée V, Cortes M, Dorchêne D, Arthur M, Mainardi JL. Bactericidal and intracellular activity of $\beta$-lactams against Mycobacterium abscessus. J Antimicrob Chemother. 2016;71(6):1556-63.

65. Ferro BE, Srivastava S, Deshpande D, Pasipanodya JG, van Soolingen D, Mouton JW, et al. Tigecycline is highly efficacious against Mycobacterium abscessus pulmonary disease. Antimicrob Agents Chemother. 2016;60(5):2895-900

66. Graham ML, Prescott MJ. The multifactorial role of the 3 Rs in shifting the harm-benefit analysis in animal models of disease. Eur J Pharmacol. 2015;759:19-29.

67. Wu X, van Dijk EM, Bos IST, Kistemaker LEM, Gosens R. Mouse lung tissue slice culture. Methods Mol Biol. 2019;1940:297-311.

\section{Publisher's Note}

Springer Nature remains neutral with regard to jurisdictional claims in published maps and institutional affiliations.

Ready to submit your research? Choose BMC and benefit from:

- fast, convenient online submission

- thorough peer review by experienced researchers in your field

- rapid publication on acceptance

- support for research data, including large and complex data types

- gold Open Access which fosters wider collaboration and increased citations

- maximum visibility for your research: over 100M website views per year

At BMC, research is always in progress.

Learn more biomedcentral.com/submissions 